\title{
Role of intracellular and extracellular annexin A1 in migration and invasion of human pancreatic carcinoma cells
}

Raffaella Belvedere, Valentina Bizzarro, Ada Popolo, Fabrizio Dal Piaz, Michele Vasaturo, Paola Picardi, Luca Parente and Antonello Petrella*

\begin{abstract}
Background: Annexin A1 (ANXA1), a 37 kDa multifunctional protein, is over-expressed in tissues from patients of pancreatic carcinoma (PC) where the protein seems to be associated with malignant transformation and poor prognosis.

Methods: The expression and localization of ANXA1 in MIA PaCa-2, PANC-1, BXPC-3 and CAPAN-2 cells were detected by Western Blotting and Immunofluorescence assay. Expression and activation of Formyl Peptide Receptors (FPRs) were shown through flow cytometry/PCR and FURA assay, respectively. To investigate the role of ANXA1 in PC cell migration and invasion, we performed in vitro wound-healing and matrigel invasion assays.

Results: In all the analyzed PC cell lines, a huge expression and a variable localization of ANXA1 in sub-cellular compartments were observed. We confirmed the less aggressive phenotype of BXPC-3 and CAPAN-2 compared with PANC-1 and MIA PaCa-2 cells, through the evaluation of Epithelial-Mesenchymal Transition (EMT) markers. Then, we tested MIA PaCa-2 and PANC-1 cell migration and invasiveness rate which was inhibited by specific ANXA1 siRNAs. Both the cell lines expressed FPR-1 and -2. Ac2-26, an ANXA1 mimetic peptide, induced intracellular calcium release, consistent with FPR activation, and significantly increased cell migration/invasion rate. Interestingly, in MIA PaCa-2 cells we found a cleaved form of ANXA1 ( $33 \mathrm{kDa}$ ) that localizes at cellular membranes and is secreted outside the cells, as confirmed by MS analysis. The importance of the secreted form of ANXA1 in cellular motility was confirmed by the administration of ANXA1 blocking antibody that inhibited migration and invasion rate in MIA PaCa-2 but not in PANC-1 cells that lack the $33 \mathrm{kDa}$ ANXA1 form and show a lower degree of invasiveness. Finally, the treatment of PANC-1 cells with MIA PaCa-2 supernatants significantly increased the migration rate of these cells.
\end{abstract}

Conclusion: This study provides new insights on the role of ANXA1 protein in PC progression. Our findings suggest that ANXA1 protein could regulate metastasis by favouring cell migration/invasion intracellularly, as cytoskeleton remodelling factor, and extracellularly like FPR ligand.

Keywords: Annexin A1, Pancreatic cancer, Formyl peptide receptors, Cell migration, Cell invasion

\section{Background}

Pancreatic carcinoma (PC) is one of the most aggressive gastrointestinal malignancies worldwide, with poor prognosis [1] and a 5-year survival rate of 3-5\% [2].

The current standard treatment for patients affected by PC is surgery, radiations and drugs as gemcitabine and TS-1 [3]. However, most patients present a marked

\footnotetext{
* Correspondence: apetrella@unisa.it

Department of Pharmacy, University of Salerno, via Giovanni Paolo II 132, 84084 Fisciano, SA, Italy
}

\section{Biomed Central

resistance to chemo- and radiotherapy that impacts their therapeutic effects. Moreover, PC invades progressively and metastasizes to liver and lymph nodes during early stages without remarkable symptoms so that, surgery is not an option for the majority of these patients that present rapid relapse $[4,5]$.

Tumour metastases are the most common causes of death in cancer patients and represent the utmost challenge for cancer treatment. In particular cell migration and invasion play a crucial role in the progression of cancer since 
their deregulation causes tumour metastasis [6]. Thus, a better understanding of the mechanisms underlying these processes is important for the development of novel anticancer agents in order to improve clinical outcome.

Annexin A1 (ANXA1) is a key member of the A subfamily and belongs to the multi-gene family of annexins. ANXA1 exhibits calcium-mediated phospholipid binding properties and participates in many physiopathological processes, including inhibition of cell proliferation, antiinflammatory effects, regulation of cell migration, differentiation and death [7].

ANXA1 appearance is in a tissue- and tumour-specific manner and its anomalous expression is closely related to cancer progression $[8,9]$. Up-regulated ANXA1 expression was correlated with tumour progression in urothelial carcinoma, glioma, colon carcinoma and lung squamous carcinoma, whereas down-regulated ANXA1 expression was observed in prostate, oral and gastric cancer progression. This suggests that ANXA1 influences cancer progression in different ways and that it may have different sub-cellular localizations that determine its functions [10].

One of this ways could be due to ANXA1 well known ability to bind F-actin in a $\mathrm{Ca}^{2+}$-dependent manner since the protein has been found to accumulate concomitantly with the appearance of F-actin at the ruffles and at the cell-cell contacts in several biological systems [11]. However, the relevance and the significance of this property remain unclear to date, also in cancer cells where the motility is driven by reorganization of the cytoskeleton and of the contacts between the cell and the matrix.

ANXA1 has been shown to localize to the cell surface of various cell types where it is thought to be important in biological functions as myoblast and skin fibroblast migration and cytoskeleton reorganization [12,13]. The extracellular form of ANXA1 has been as well described to play a role in cancer cell invasion and metastasis. The most significant example is breast cancer, where the pro-invasive effect of ANXA1 is triggered by the interaction with the Formyl Peptide Receptors (FPRs) [14]. The regulatory action on cell surface by extracellular ANXA1 is indeed thought to be mediated by signalling through FPRs $[12,13,15]$. FPRs are G-protein coupled chemoattractant receptors, which can sense gradients of bacterial peptides such as formyl-Methionine-LeucinePhenylalanine (fMLP) and thereby direct leukocytes towards sites of bacterial infection [16]. Three human FPR family members have been identified including FPR-1, FPR-2, and FPR-3. Ligand binding to FPR activates a number of downstream effector enzymes including phospholipase $\mathrm{C}$, catalyzing the cleavage of phosphatidyl inositol 4,5-biphosphate into secondary messengers inositol 1,4,5-triphosphate and diacylglycerol leading to calcium mobilization and activation of protein kinase $\mathrm{C}$ (PKC) [16-18].
Previous studies have shown that tumour cells from highly malignant human glioma specimens express FPR1 [19]; subsequently it has been shown that ANXA1 released by necrotic human glioblastoma cells was able to stimulate tumour cell growth through FPR-1 [20]. Interestingly, it has also been shown that the translocation of ANXA1 to the cell surface is partially responsible for promoting cell migration and invasion in colorectal carcinoma cell line SKCO-15, indicating an autocrine/ paracrine role for membrane ANXA1 [21].

Despite the identification of ANXA1 as one of the several proteins that is differentially expressed during the progression of tumours to more malignant states, a functional role for ANXA1 in PC advancing is lacking. The aim of our study is to investigate the role of ANXA1 in human PC progression, in particular we focused on its involvement in cancer cell migration and invasiveness.

\section{Methods}

\section{Cell cultures}

MIA PaCa-2, human PC cells, were cultured in DMEM (Lonza) containing L-Glutamine $2 \mathrm{mM}, 10 \%$ heatinactivated fetal bovine serum (FBS; Lonza) and 2,5\% heat inactivated horse serum (HS; Lonza). PANC-1, human pancreatic epithelioid carcinoma cells, were kept in DMEM containing L-Glutamine $2 \mathrm{mM}$ and $10 \%$ heatinactivated fetal bovine serum (FBS; Lonza). BxPC-3, human pancreatic adenocarcinoma cells, were cultured in RPMI 1640 (Lonza) containing 10\% heat-inactivated fetal bovine serum (FBS; Lonza). CAPAN-2, human PDAC cells, were kept in McCoy's 5a Medium Modified (Lonza) with $10 \%$ heat-inactivated fetal bovine serum (FBS; Lonza). All the media were supplemented with antibiotics $(10000 \mathrm{U} / \mathrm{ml}$ penicillin and $10 \mathrm{mg} / \mathrm{ml}$ streptomycin; Lonza). Cell lines were purchased from ATCC (Rockville, USA) and were grown at $37^{\circ} \mathrm{C}$ in $5 \% \mathrm{CO}_{2}-95 \%$ air humidified atmosphere.

\section{Cytosol and membrane extracts}

MIA PaCa- 2 and PANC-1 cells were washed twice with PBS, detached with trypsin-EDTA $1 \times$ in PBS (Euroclone), harvested in PBS and centrifuged for 5 minutes at $600 \times \mathrm{g}$ at $4^{\circ} \mathrm{C}$. After that, the pellets were resuspended in $4 \mathrm{ml}$ of lysis buffer (Tris $\mathrm{HCl} 20 \mathrm{mM}, \mathrm{pH}$ 7,4; sucrose $250 \mathrm{mM}$; DTT $1 \mathrm{mM}$; protease inhibitors, EDTA $1 \mathrm{mM}$ in water), sonicated (5 seconds pulse - 9 seconds pause for $2 \mathrm{mi}$ nutes, amplitude 42\%) and then centrifuged at $4{ }^{\circ} \mathrm{C}$ for 10 minutes, at $5000 \times \mathrm{g}$. The obtained supernatants were ultra-centrifuged for 1 hour at $100000 \times \mathrm{g}$ at $4^{\circ} \mathrm{C}$, until to get new supernatants that represent cytosol extracts. Each resulting pellet was resuspended in $4 \mathrm{ml}$ of lysis buffer and ultra-centrifuged for 1 hour at $100000 \times \mathrm{g}$ at $4^{\circ} \mathrm{C}$. The pellets were then resuspended in $250 \mu \mathrm{l}$ of solubilization buffer (Tris $\mathrm{HCl} 20$ mM, pH 7,4; DTT 1 mM; EDTA 
$1 \mathrm{mM}$; Triton X-100 1\%, in water) and left overnight on orbital shaker at $4^{\circ} \mathrm{C}$. After that, the solution was centrifuged for 30 minutes at $50000 \times \mathrm{g}$ at $4^{\circ} \mathrm{C}$ : the supernatants represent membrane extracts. To detect membrane expression of ANXA1 we also use an EDTA Wash method, as previously described [22].

\section{Nuclear extracts}

MIA PaCa- 2 and PANC- 1 cells were washed twice with PBS, detached with trypsin-EDTA $1 \times$ in PBS (Euroclone), harvested in PBS and centrifuged for 5 minutes at $600 \times \mathrm{g}$ at $4^{\circ} \mathrm{C}$. The pellets were resuspended in $500 \mu \mathrm{l}$ of buffer $\mathrm{A}$ (Hepes pH $7.910 \mathrm{mM}$, EDTA pH $8.01 \mathrm{mM}, \mathrm{KCl} 60 \mathrm{mM}$, N-P40 0.2\%, DTT $1 \mathrm{mM}$, PMSF $1 \mathrm{mM}$, protease inhibitors) and then left on ice for 10 minutes. After that, the samples were centrifuged at $660 \times \mathrm{g}$ for 5 minutes at $4^{\circ} \mathrm{C}$, resuspended in $50 \mu \mathrm{l}$ of buffer $\mathrm{B}$ (Tris $\mathrm{HCl} \mathrm{pH} 7.8$ $250 \mathrm{mM}, \mathrm{KCl} 60 \mathrm{mM}$, DTT $1 \mathrm{mM}$, PMSF $2 \mathrm{mM}$, glycerol $20 \% \mathrm{v} / \mathrm{v}$ in PBS) and centrifuged again at $9500 \times \mathrm{g}$ for 15 minutes at $4^{\circ} \mathrm{C}$. The obtained pellets were resuspended in $100 \mu \mathrm{l}$ of buffer C (Hepes pH $7.910 \mathrm{mM}$, EDTA pH 8.0 $1 \mathrm{mM}, \mathrm{KCl} 60 \mathrm{mM}$, DTT $1 \mathrm{mM}$, PMSF $1 \mathrm{mM}$, protease inhibitors) and centrifuged at $660 \times \mathrm{g}$ for 5 minutes at $4^{\circ} \mathrm{C}$. The samples were then washed twice with $1 \mathrm{ml}$ of buffer $C$, resuspended in $50 \mu \mathrm{l}$ of buffer B and exposed to 3 cycles of freeze/thawing. Finally, the samples were centrifuged at $9500 \times \mathrm{g}$ for 15 minutes at $4^{\circ} \mathrm{C}$ : the pellets represent the nuclear extracts.

\section{Supernatant analysis}

Cell growth media were harvested, frozen at $-80^{\circ} \mathrm{C}$ and lyophilized. Dried samples were suspended in lysis buffer containing protease inhibitors and left at $4^{\circ} \mathrm{C}$ for 30 minutes. After centrifugation, the supernatants were filtered through Amicon Ultra-15, PLTK Ultracel-PL Membrane, $10 \mathrm{kDa}$ (Millipore). The filtrates were loaded on a Chromabond HR-X micro-column (Macherey-Nagel) and eluted with 70\% ACN and 95\% ACN. Eluted samples were analyzed by LC/MS/MS using an Orbitrap XL instrument (Thermo Scientific) as reported elsewhere [23].

\section{Western blotting analysis}

Expression of ANXA1 was examined by SDS-PAGE. Total intracellular proteins were extracted from the cells by freeze/thawing in lysis buffer containing protease inhibitors. Protein content was estimated according to Biorad protein assay (BIO-RAD). Samples $(20 \mu \mathrm{g}$ protein) were loaded onto $10 \%$ denaturing-polyacrylamide gel and separated by SDS-PAGE. The separated proteins were then transferred electrophoretically to nitrocellulose membranes (Immobilon-NC, Millipore). Membranes were blocked with 5\% non-fat dry milk in TBS-Tween $20(0.1 \% \mathrm{v} / \mathrm{v})$ and then incubated overnight at $4^{\circ} \mathrm{C}$ with the primary antibodies. Proteins were visualized using the enhanced chemiolumi- nescence detection system (Amersham Pharmacia Biotech) after incubation overnight at $4^{\circ} \mathrm{C}$ with primary polyclonal antibody against ANXA1 (1:10000; Invitrogen) and monoclonal a-tubulin (1:1000; Sigma-Aldrich) and then at RT with an appropriate secondary rabbit or mouse antibody (1:5000; Sigma-Aldrich). Immunoreactive protein bands were detected by chemioluminescence using enhanced chemioluminescence reagents (ECL; Amersham), the blots were exposed and analyzed to Las4000 (GE Healthcare Life Sciences).

\section{siRNA transfection}

The 4, 6, 7 and 8 siRNA sequences against ANXA1 were purchased from Qiagen and used at a final concentration of $5 \mathrm{nM}$. siRNA Oligo-Scrambled (Santa Cruz Biotechnology) was used as control at the same concentration. siRNAs were transfected using Lipofectamine 2000 Reagent (Life technologies Corporation), according to the manufacturer's instructions. Cells were harvested after 72 hours from transfection.

\section{Confocal microscopy}

After the specific time of incubation, MIA PaCa-2, PANC-1, BxPC-3 and CAPAN-2 cells were fixed in pformaldehyde ( $4 \% \mathrm{v} / \mathrm{v}$ in PBS) for 5 minutes. The cells were permeabilized in Triton X-100 (0.5\% v/v in PBS) for 5 minutes, and then incubated in goat serum $(20 \% \mathrm{v} / \mathrm{v}$ PBS) for 30 minutes, and with rabbit anti-ANXA1 antibody (1:100; Invitrogen), mouse anti-FAK (1:100; BD Transduction Laboratories), mouse anti-E-cadherin (1:250; Santa Cruz Biotechnology) and/or mouse anti-vimentin (1:500; Santa Cruz Biotechnology) overnight at $4^{\circ} \mathrm{C}$. After two washing steps with PBS, cells were incubated with anti-rabbit and/or anti-mouse AlexaFluor (488 and/or 555; 1:1000; Molecular Probes) for 2 hours at RT and then with FITC-conjugated anti-F-actin $(5 \mu \mathrm{g} / \mathrm{ml}$; Phalloidin-FITC, Sigma) for 30 minutes at RT in the dark. The coverslips were mounted in glycerol (40\% v/v PBS). A Zeiss LSM 710 Laser Scanning Microscope (Carl Zeiss MicroImaging $\mathrm{GmbH}$ ) was used for data acquisition. To detect nucleus, samples were excited with a $458 \mathrm{~nm}$ Ar laser. A $555 \mathrm{~nm}$ $\mathrm{He}-\mathrm{Ne}$ laser was used to detect emission signals from ANXA1 stain. Samples were vertically scanned from the bottom of the coverslip with a total depth of $5 \mathrm{~mm}$ and a $63 \times$ (1.40 NA) Plan-Apochromat oil-immersion objective. Images were generated with Zeiss ZEN Confocal Software (Carl Zeiss MicroImaging GmbH).

\section{Flow cytometry}

MIA PaCa-2 and PANC-1 cells were harvested at a number of $1 \times 10^{6}$ and centrifuged at $30000 \times \mathrm{g}$ for 5 minutes. The pellets were then incubated on ice for 1 hour in $100 \mu \mathrm{l}$ of PBS containing a primary polyclonal antibody against FPR-1 (1:500, Santa Cruz Biotechnology) or a primary 
monoclonal antibody against FPR-2 (1:100, Genovac). After that, MIA PaCa-2 and PANC-1 cells were washed twice and incubated on ice for 1 hour in $100 \mu \mathrm{l}$ of PBS containing AlexaFluor 488 anti-rabbit (1:1000; Molecular Probes) or AlexaFluor 488 anti-mouse (1:1000; Molecular Probes). The cells were analyzed with Becton Dickinson FACScan flow cytometer using the Cells Quest program.

\section{PCR}

MIA PaCa-2 and PANC-1 cells were seeded at an initial density of $1 \times 10^{6}$ in a $100 \mathrm{~mm}$ Petri dish and incubated for 48 hours in growth medium allowing cells to reach $90 \%$ confluency. Total RNA was extracted from cells using Trizol (Invitrogen) [24]. Total RNA (5 $\mu$ g) was used to synthesize cDNA using a reverse transcription kit (Roche). PCR was conducted by using the following primers:

FPR-1 primer pair: (fwd 5'-CAA GAT GGA GAC AAA TTC CTC TC-3') and (rev 3'-GAG CAG AGC CAT CAC CCA GGG CCC AA-5');

FPR-2 primer pair: (fwd 5'-CTG TAC TTT CAA CTT TGC ATC C-3') and (rev 3'-ATT TCC CAA CTC CAC TTA CC-5');

The predicted FPR-1 and FPR-2 products are 469 bp and $773 \mathrm{bp}$, respectively. The FPR-1 and FPR-2 genes were amplified using PCR under the following conditions: pre-denaturation at $94^{\circ} \mathrm{C}$ for 2 minutes, 35 cycles of denaturation at $94^{\circ} \mathrm{C}$ for 30 seconds, annealing at $60^{\circ} \mathrm{C}$ for 30 seconds, extension at $72^{\circ} \mathrm{C}$ for 30 seconds and a final extension at $72^{\circ} \mathrm{C}$ for 10 minutes. The products were stored at $4^{\circ} \mathrm{C}$. A portion $(5 \mu \mathrm{l})$ of the PCR product was electrophoresed on a $1 \%$ agarose gel in a Tris-acetateEDTA buffer. The gel was stained with ethidium bromide and was scanned and analysed to Las4000 (GE Healthcare Life Sciences).

\section{Measurement of intracellular $\mathrm{Ca}^{2+}$ signalling}

Intracellular $\mathrm{Ca}^{2+}$ concentrations $\left[\mathrm{Ca}^{2+}\right]$ were measured using the fluorescent indicator dye Fura 2-AM, the membrane-permeant acetoxymethyl ester form of Fura 2 , as previously described [25], with minor revisions. Briefly, MIA PaCa- 2 and PANC- 1 cells $\left(5 \times 10^{3} /\right.$ multiwell 24 culture dishes) were washed in PBS and re-suspended in $1 \mathrm{ml}$ of Hank's balanced salt solution (HBSS) containing $5 \mu \mathrm{M}$ Fura 2-AM for 45 minutes. Thereafter, cells were washed with the same buffer to remove excess of Fura 2$\mathrm{AM}$ and incubated in $\mathrm{Ca}^{2+}$-free HBSS/0.5 mM EGTA buffer for 15 minutes to allow hydrolysis of Fura 2-AM into its active-dye form, Fura 2. MIA PaCa-2 and PANC-1 cells were then transferred to the spectrofluorimeter (Perkin-Elmer LS-55). Treatment with ionomycin $(1 \mu \mathrm{M})$, fMLP (50 nM, Sigma Aldrich), with Ac 2-26 (1 $\mu \mathrm{M}$, Tocris Bioscience) or Boc-1 (10 $\mu \mathrm{M}$, Bachem AG) was carried out by adding the appropriate concentrations of each substance into the cuvette in $\mathrm{Ca}^{2+}$-free HBSS/0.5 mM EGTA buffer. The excitation wavelength was alternated between 340 and $380 \mathrm{~nm}$, and emission fluorescence was recorded at $515 \mathrm{~nm}$. The ratio of fluorescence intensity of 340/ $380 \mathrm{~nm}$ (F340/F380) was used to estimate intracellular free calcium. Results are indicated as delta increase of fluorescence ratio (F340/F380 nm) induced by ionomycin - basal fluorescence ratio (F340/F380 nm).

\section{In vitro wound-healing assay}

MIA PaCa-2 and PANC-1 cells were seeded in a 12-well plastic plate at $5 \times 10^{5}$ cells per well. After 24 hours incubation, cells reached $100 \%$ confluency and a wound was produced at the centre of the monolayer by gently scraping the cells with a sterile plastic p10 pipette tip. After removing incubation medium and washing with PBS, cell cultures were incubated in the presence of fMLP $(50 \mathrm{nM})$, Ac2-26 $(1 \mu \mathrm{M})$, Boc-1 $(10 \mu \mathrm{M})$ or in growth medium as control. In case of transfection with siANXA1s, cells were plated at a number of $2 \times 10^{5}$, after 24 hours were transfected with siANXA1s or with scrambled siRNAs and, 72 hours after transfection, wound was produced. The wounded cell cultures were then incubated at $37^{\circ} \mathrm{C}$ in a humidified and equilibrated $\left(5 \% \mathrm{v} / \mathrm{v} \mathrm{CO}_{2}\right)$ incubation chamber of an Integrated Live Cell Workstation Leica AF-6000 LX. A 10× phase contrast objective was used to record cell movements with a frequency of acquisition of 10 minutes. The migration rate of individual cells was determined by measuring the distances covered from the initial time to the selected time-points (bar of distance tool, Leica ASF software). For each condition five independent experiments were performed. For each wound five different positions were registered, and for each position ten different cells were randomly selected to measure the migration distances. Statistical analysis was performed by using GraphPad Prism software (GraphPad Software Inc., version 5.0). Data are presented as means \pm SEM. Values $\mathrm{p}<0.05$ were considered as significant.

\section{Matrigel invasion assay}

MIA PaCa-2 and PANC-1 invasiveness was studied using the Trans-well Cell Culture (12 mm diameter, 8.0fim pore size) purchased form Corning Incorporated (USA). The chambers were coated with Matrigel (Becton Dickinson Labware) that was diluted with 3 volumes of DMEM serum-free and stored at $37^{\circ} \mathrm{C}$ until its gelation. Cells were plated in $350 \mu \mathrm{l}$ of DMEM serum-free at a number of $9 \times 10^{4} /$ insert in the upper chamber of the trans-well. 1,4 $\mathrm{ml}$ of DMEM with or without FBS were put in the lower chamber and the trans-well was left for 24 hours at $37^{\circ} \mathrm{C}$ in $5 \% \mathrm{CO}_{2}-95 \%$ air humidified atmosphere. After that, the medium was aspirated, the filters 
were washed twice with PBS $1 \times$ and fixed with $4 \%$ pformaldehyde for 10 minutes, then with $100 \%$ methanol for 20 minutes. The filters so fixed, were stained with $0,5 \%$ crystal violet prepared from stock crystal violet (powder, Merck Chemicals) by distilled water and $20 \%$ methanol for 15 minutes. After that, the filters were washed again in PBS $1 \times$ and cleaned with a cotton bud. The number of cells that had migrated to the lower surface was counted in twelve random fields using EVOS light microscope (10×) (Life technologies Corporation).

\section{Statistical analysis}

All results are the mean \pm SEM of at least 3 experiments performed in triplicate. The optical density of the protein bands detected by Western blotting was normalized against tubulin levels. Statistical comparisons between groups were made using two-way ANOVA or unpaired, two-tailed $t$-test comparing two variables. Differences were considered significant if $\mathrm{p}<0.05$ and $\mathrm{p}<0.01$.

\section{Results}

Expression and localization of ANXA1 in PC cell lines

ANXA1 role in PC progression is poorly described. Therefore, we initially focused to define how ANXA1 is expressed and localized in several human PC cell lines as MIA PaCa-2, PANC-1, BxPC-3 and CAPAN-2. These cells show many differences about their genotype, such as Kras or p16 mutations, and phenotype, as adhesion, migration, invasion and angiogenesis capacities [26]. As shown in Figure 1A, Western blotting analyses revealed that all cell lines expressed ANXA1.

Next, we characterized MIA PaCa-2, PANC-1, BxPC3 and CAPAN-2 cells on the basis of their phenotype since the more aggressive and invasive cancer cells had a higher basal Epithelial-Mesenchymal Transition (EMT) signature [27]. Confocal microscopy analyses confirmed, as previously described [26], more aggressive features for MIA PaCa-2 and PANC- 1 as, differently from BxPC-3 and CAPAN-2, these cancer cells possess a marked mesenchymal phenotype characterized by up-regulation of the mesenchymal marker vimentin and down-regulation of the epithelial marker E-cadherin (Figure 1B,C,D) [28].

Tumour cell invasion and metastasis processes involve many proteins that are required for normal cell motility. As it is known that ANXA1 plays a role in normal cell migration $[12,13]$ and in cancer cell invasion and metastasis $[14,10]$, we also analyzed by confocal microscopy ANXA1 localization in the cellular motility structures identified by using focal adhesion kinase (FAK) or Factin staining. In the figure $1 \mathrm{E}$ (panels $\mathrm{c}, \mathrm{f}$ ) we show that ANXA1 co-localized in both MIA PaCa-2 and PANC-1 cells with FAK, a protein commonly expressed in adhesion hot spots of migrating/invasive cells. Moreover, we show an actin-like filamentous ANXA1 organization and an enrichment of the protein at burble ends and extrusions in MIA PaCa-2 cells (Figure 1E, panel i). Also in PANC-1 cells ANXA1 co-localized with $\mathrm{F}$-actin protein although this cell line is characterized by a less mesenchymal-like phenotype (Figure 1E, panel n).

\section{Effects of ANXA1 knockdown on MIA PaCa-2 and PANC-1 cell migration and invasiveness}

As it is known from previous reports and confirmed by our data using confocal microscopy, PANC-1 and MIA $\mathrm{PaCa}-2$, differentially from CAPAN-2 and BxPC-3, show a more aggressive phenotype, particularly MIA PaCa-2 that have an higher tumorigenic potential $[29,26]$.

We observed that in MIA PaCa- 2 and PANC-1 cell lines ANXA1 localized in the regions that are involved in the cell movement. As the migration/invasion processes start once cells form actin- and FAK-rich protrusions that adhere to the matrix and create the tension forces necessary for cell motility [30], we hypothesised a role for the protein in these processes. The expression of ANXA1 was greatly reduced in MIA PaCa-2 (Figure 2A) and PANC-1 (Figure 2D) cells by specific siRNA transfection. Thus a wound-healing migration assay on cellular monolayer in ANXA1 knockdown cells was performed. The confluent cultures were scraped to create a wound and cell migration was monitored by time-lapse video-microscopy at the site of the wound. We measured the migration distances of selected cells at different time points as described in Methods section. In ANXA1 knockdown MIA PaCa-2 (Figure 2B) and PANC-1 (Figure 2E) cells the rate of migration decreased in a significant manner, if compared with the wild type control and with scrambled RNA transfected cells.

The matrigel invasion assay was also performed in ANXA1 knockdown MIA PaCa-2 and PANC-1 cells to investigate the role of ANXA1 on their invasion ability. As shown in Figure $2 \mathrm{C}$ and $2 \mathrm{~F}$, siRNAs against ANXA1 markedly suppressed the invasiveness of both PC cell lines. To confirm the technical efficiency of our experiment, we used a serum free control to eliminate any chemoattractant condition: in this way we found significantly less invading cells on the lower surface of matrigel (data not shown).

\section{Localization and cleavage of endogenous ANXA1 in MIA PaCA-2 cells}

Cellular migration and invasion events can be triggered by a number of molecular signals, such as chemoattractants and mechanical forces, which are sensed by receptors on the cell surface or within cells to lead to a migratory response [31].

The extracellular form of ANXA1 has been described to play a role in cancer cell invasion and metastasis. Although the protein does not possess classical signal sequences to 


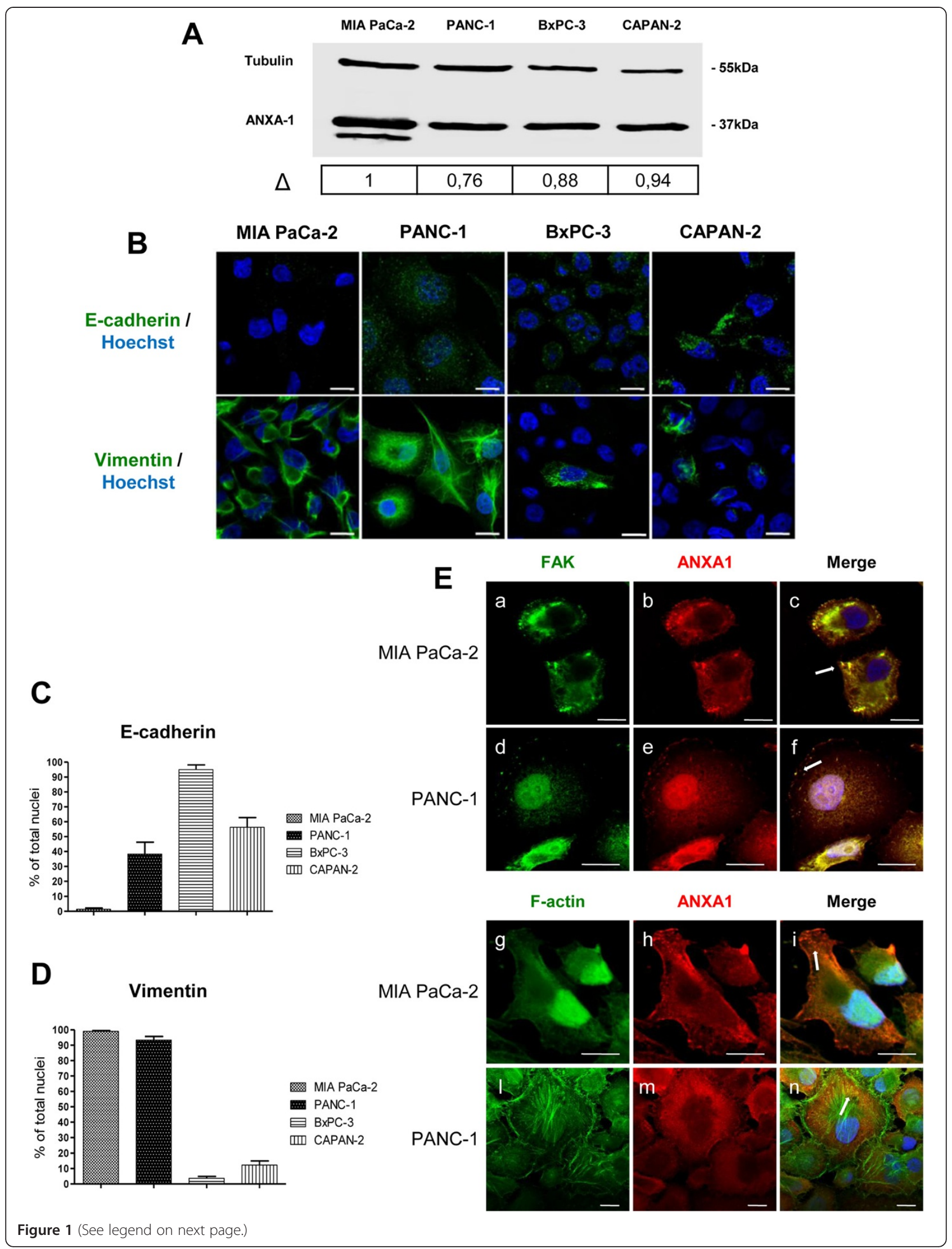


(See figure on previous page.)

Figure 1 Expression and localization of ANXA1 in human PC cells. A, Total ANXA1 expression in MIA PaCa-2, PANC-1, BXPC-3 and CAPAN-2 cells was analyzed by Western blot with anti-ANXA1 antibody. $\Delta$ represents ANXA1 fold change by densitometry. B, Cultured human MIA PaCa-2, PANC-1, BXPC-3 and CAPAN-2 cells fixed and labelled with fluorescent antibody against E-cadherin and vimentin (green). C, D, Quantitative analysis of E-cadherin and vimentin protein expression in MIA PaCa-2, PANC-1, BxPC-3 and CAPAN-2 cells. Histograms represent the percentage of E-cadherin and vimentin positive cells on total DAPI positive nuclei. Results are mean \pm standard deviation from three independent experiments, where at least 100 nuclei per cell line were counted. $\mathbf{E}$, Immunofluorescence analysis to detect FAK (panels a, d), ANXA1 (panels b, e, h, m), and F-actin (panels g, l) in MIA PaCa-2 and PANC-1. Nuclei were stained with DAPI. The merged image shows overlapping localization of the proteins (panels $c, f, I, n)$. Magnification 63x. The data are representative of 5 experiments with similar results. Bar $=10 \mu \mathrm{m}$.

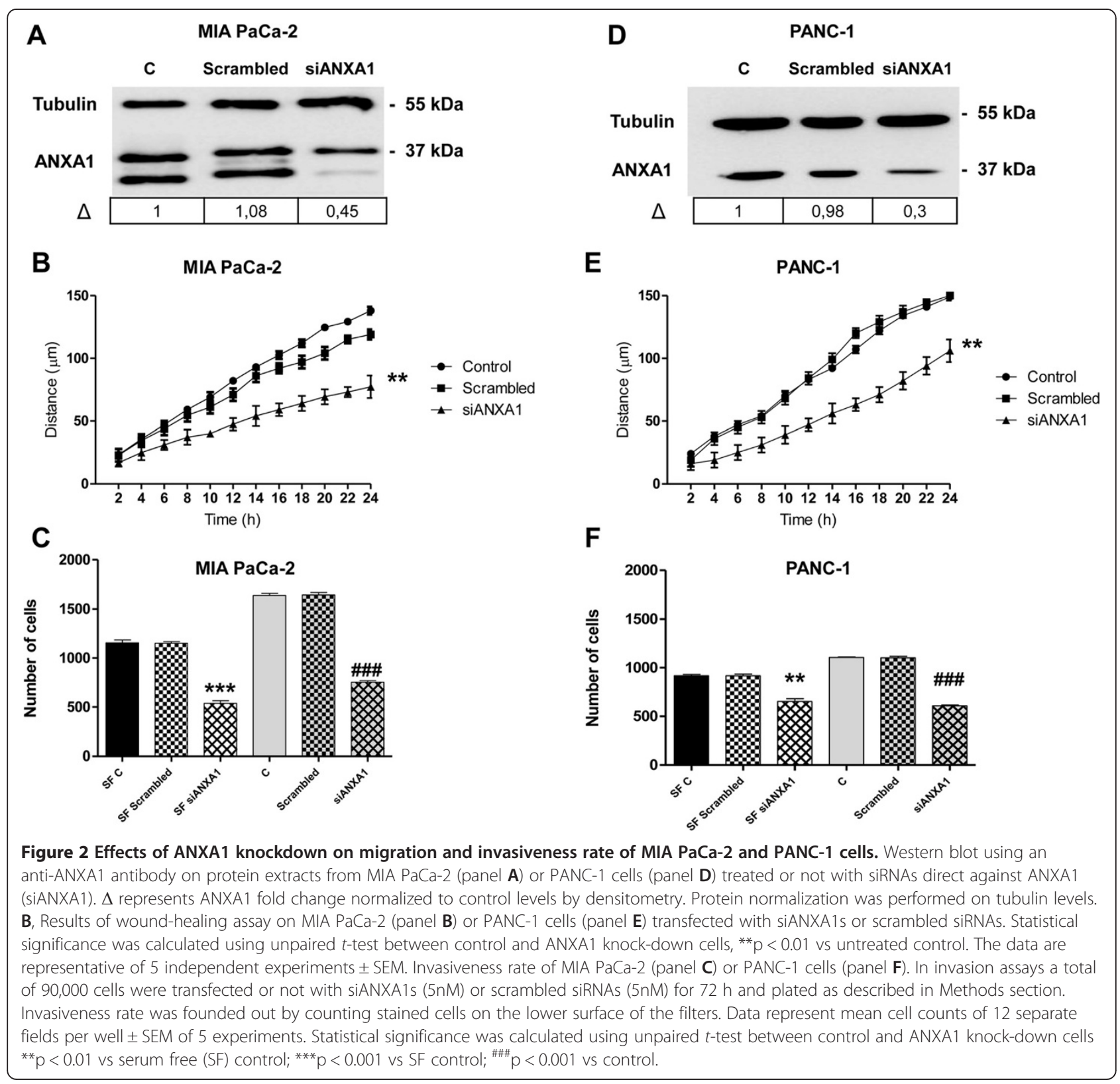


target the protein for export, both the full-length and truncated forms are often observed in extracellular environments. Moreover, it appears that proteolytic cleavage of ANXA1 is required for protein secretion, because the majority of ANXA1 released from neutrophils is Nterminally cleaved [32-38]. Based on this information, our characterization experiments continued with the analysis by Western blot of ANXA1 expression in subcellular compartments of MIA PaCa-2 cells. In particular, we obtained membrane, cytosol and nuclear protein extracts as described in Methods section. The ANXA1 membrane expression was detected by both fractioned protein extracts and EDTA wash, with which we obtained the proteins that bind plasma membrane through calcium. In MIA PaCa-2 extracts, we found both, full length $(37 \mathrm{kDa})$ and cleaved $(33 \mathrm{kDa})$ forms of ANXA1 protein at plasma membrane and in the cytosol but not in the nucleus where only the $37 \mathrm{kDa}$ ANXA1 form was expressed. Conversely, PANC-1 didn't show the ANXA1 cleaved form and the protein expression in sub-cellular compartments was characterized by a small amount onto membrane and in the nucleus, if compared with MIA $\mathrm{PaCa}-2$ cells.

Both full length (37 kDa) and cleaved (33 kDa) forms of ANXA1 were also observed in MIA PaCa-2 supernatants, whereas no protein secretion was observed in the PANC-1 supernatants (Figure 3).

\section{Expression and activation of FPRs in MIA PaCa-2 and PANC-1 cells}

Cancerous cell capability to migrate and invade tissues is a decisive aspect of cancer progression and entails the coordination of several cellular events, such as cytoskeletal reorganization, dynamic cell-matrix adhesion and remodelling [30].

Regulatory action on cell surface by extracellular ANXA1 is reported to be mediated by signalling through FPRs $[12-13 ; 20,21]$ that are supposed to regulate cell migration by actin polymerization.

In order to verify the role of ANXA1-FPR interaction in MIA PaCa-2 and PANC-1 cell migration and invasiveness, we first assessed FPR expression in these cell lines by cytofluorimetric analysis (Figure 4A): we found that FPR-1 and FPR-2 were expressed in both cell lines. These findings were confirmed by qualitative PCR (Figure 4B).

It is known that the interaction between ANXA1 and FPRs causes a series of cellular responses, such as the ERK phosphorylation and the increase of intracellular $\left[\mathrm{Ca}^{2+}\right]$ concentration. The N-terminal mimetic peptide of ANXA1, Ac2-26, can activate all three human FPRs, promoting calcium fluxes, and cell locomotion. To determine whether ligand binding to FPRs induces similar signal transduction in MIA PaCa-2 and PANC-1, we examined the stimulated release of calcium from intracellular stores. Cells were incubated in $\mathrm{Ca}^{2+}$ free medium and loaded with the fluorescent calcium indicator FURA2 AM before stimulation with Ac2-26 (1 $\mu \mathrm{M})$ or the natural FPR agonist fMLP (50 $\mathrm{nM}$ ) together or not with the FPR pharmacological antagonist Boc-1 $(10 \mu \mathrm{M})$ that is able to antagonize all three human FPR isoforms. The spectrofluorimetric assay (Figure 4, panels C and D) shows that fMLP and peptide Ac2-26 were able to increase the mobilization of intracellular $\mathrm{Ca}^{2+}$ in both MIA PaCa-2 and PANC-1 cells. In fact, no significant differences between ionomycin (used as reference compound) and fMLP or Ac2-26 were observed. The effects of fMLP and Ac2-26 peptides were inhibited by the pharmacological pan-antagonist Boc-1 in both cell lines.

\section{Effects of extracellular ANXA1 on MIA PaCa-2 and PANC-1 cells}

To determine if ANXA1 influences cell migration acting through FPRs, we performed a wound-healing migration assay on cellular monolayer in both the analyzed cell lines.

For MIA PaCa-2, results in Figure 5A showed an increase in migration speed of cells treated with Ac2-26 $(1 \mu \mathrm{M})$ or fMLP $(50 \mathrm{nM})$ compared to control cells. The FPR pan-antagonist Boc-1 $(10 \mu \mathrm{M})$ significantly inhibited basal and stimulated migration. Interestingly, an ANXA1 blocking antibody was able to reduce in a significant manner MIA PaCa-2 cell migration (Figure 5B).

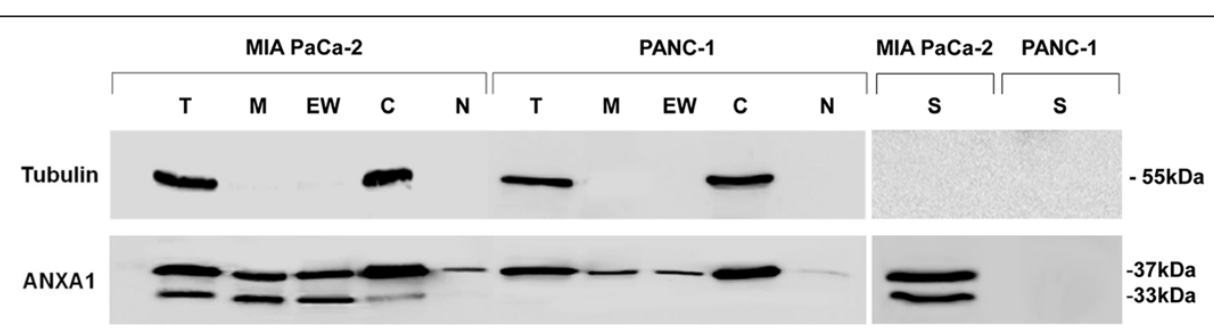

Figure 3 Expression and localization of cleaved and secreted form of ANXA1 from MIA PaCa-2 and PANC-1 cells. Cellular compartments were obtained as described in Methods section. Total (T), membrane (M), EDTA Wash (EW), cytosolic (C), nuclear (N) and supernatant (S) ANXA1 expression in protein extracts from MIA PaCa-2 and PANC-1 was examined by Western blot with anti-ANXA1 antibody. The protein bands were normalized on tubulin levels. The data are representative of 5 experiments with similar results. 


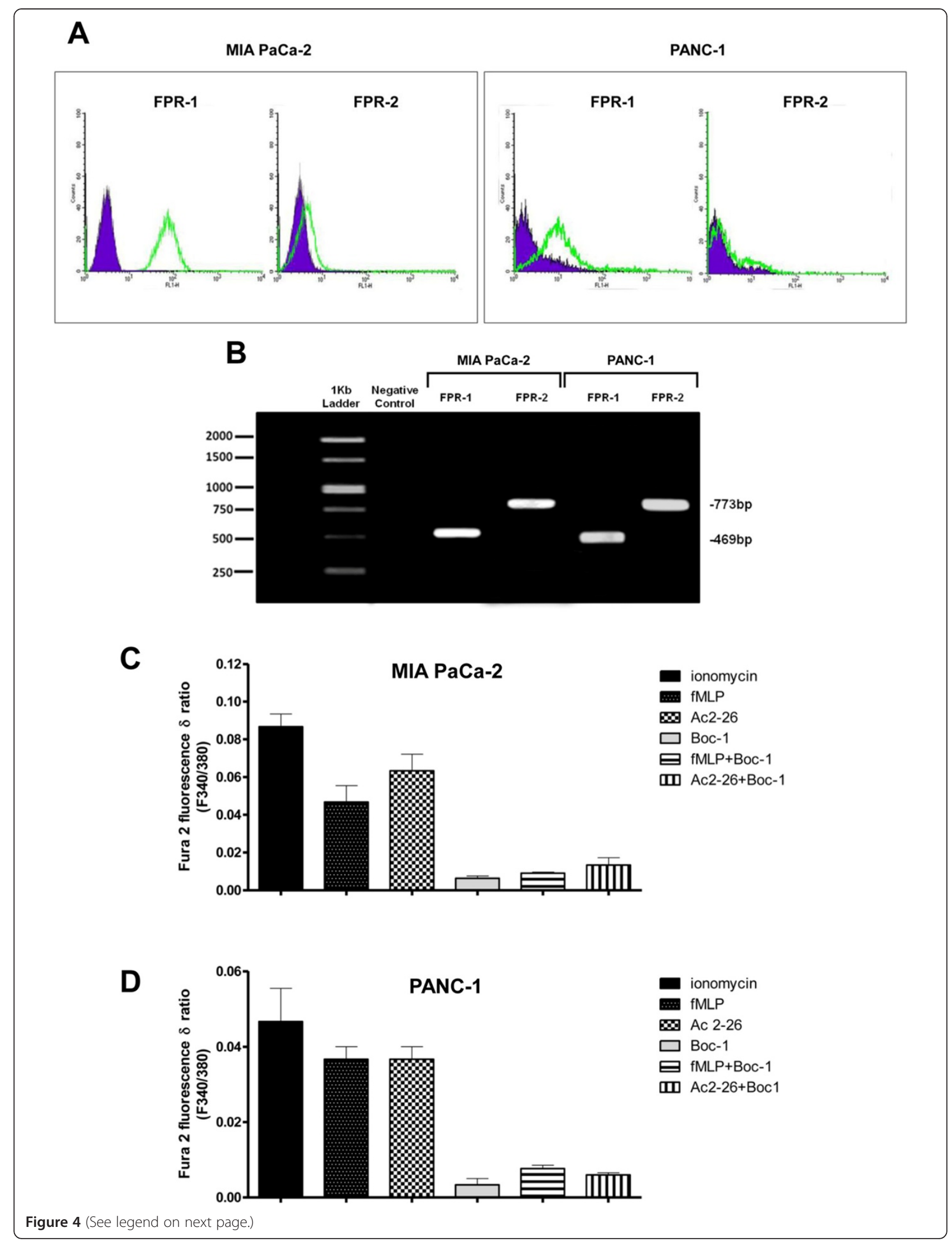


(See figure on previous page.)

Figure 4 FPR-1 and 2 expression and activation in MIA PaCa-2 and PANC-1 cells. A, Cell surface expression of FPR-1 and FPR-2 in MIA PaCa-2 and PANC-1 cells was analyzed by flow cytometry. The violet areas in the plots are relative to secondary antibody alone. FPR-1 and FPR-2 signals are showed with green bends. B, Expression of FPR-1 and FPR-2 in MIA PaCa-2 and PANC-1 cells analyzed by PCR. Effects of fMLP (50 nM), Ac-2-26 (1 $\mu \mathrm{M})$ and FPR pan-antagonist Boc-1 $(10 \mu \mathrm{M})$ on the FPR-induced rise in intracellular Ca ${ }^{2+}$ in MIA PaCa-2 (panel C) or PANC-1 cells (panel D). Cells were treated as described in Methods section. The histograms show the fluorescence ratio calculated as F340/F380 nm in absence of extracellular $\mathrm{Ca}^{2+}$. Control represents ionomycin-stimulated cells. Data are means \pm SEM $(n=5)$.

The role of ANXA1 in cancer progression is still discussed; this protein may have specific functions in different tumoral models. For example, in gastric and colon carcinomas ANXA1 has a pro-invasive role through its interaction with FPRs [15,21].

When treated with Ac2-26 (1 $\mu \mathrm{M})$ and fMLP (50 nM), MIA PaCa- 2 cells showed an increased invasion speed through coating of matrigel. Again, Boc-1 antagonist $(10 \mu \mathrm{M}$, Figure $5 \mathrm{C})$ reduced in a significant manner MIA PaCa-2 stimulated cell invasion. An ANXA1 blocking antibody was also able to inhibit basal cell invasion (Figure 5D).

At the same time, we used PANC-1 cell line as basis for comparison, as these cells did not show either the ANXA1 cleaved form or the externalized one. Similarly for MIA PaCa-2, results of the wound-healing migration assay on cellular monolayer showed an increase in migration speed of the cells treated with Ac2-26 $(1 \mu \mathrm{M})$ or fMLP $(50 \mathrm{nM})$ when compared to control cells and a reverted effect in cells treated with the pan-antagonist Boc-1 $(10 \mu \mathrm{M})$ (Figure 5E). Interestingly, ANXA1 blocking antibody had no effects on PANC-1 cell motility (Figure 5F). In order to verify whether the absence of extracellular ANXA1 in PANC-1 cell line was also implied in a different invasiveness rate, we performed a matrigel invasion assay. When treated with Ac2-26 $(1 \mu \mathrm{M})$ and fMLP (50 nM), PANC-1 cells showed a large invasion speed through coating of matrigel. In both of cases, experimental points were compared with non treated control or with Boc-1 antagonist $(10 \mu \mathrm{M})$ treated cells (Figure 5G). ANXA1 blocking antibody had no effects on PANC-1 invasiveness (Figure $5 \mathrm{H}$ ).

Effects of MIA PaCa-2 supernatants on PANC-1 cell migration Our data suggest a double role of ANXA1 in PC cell motility. In one way the protein acts in the intracellular environment thanks to its involvement in cytoskeleton reorganization, as confirmed by immunofluorescence assay showed in Figure 1E. In another one, ANXA1 externalized form appears to bind FPRs and trigger some molecular pathways that lead to cell migration and invasion. Based on these findings, we focused on the appearance of a $33 \mathrm{kDa}$ form only in MIA PaCa-2 cells, both in total (Figure 1A) and supernatant extracts (Figure 3). Therefore, in order to detect possible ANXA1 fragments released from the cells a multi-step fractionation of MIA $\mathrm{PaCa}-2$ supernatants was performed. Obtained samples were analyzed by LC-HRMS/ MS as described in Methods section. A peptide showing a molecular weight of 2744.324 was detected; on the basis of its molecular weight and of the CID induced fragmentation spectrum (Figure 6A), this peptide was identified as the fragment 4-26 of ANXA1.

Furthermore, we considered the higher migratory and invasive rate of MIA PaCa-2 compared with PANC-1 cells [26]. In order to confirm that the secreted forms of ANXA1 protein were able to induce PC cell migration and invasion in autocrine and paracrine manner, we performed further experiments adding MIA PaCa-2 supernatants to PANC-1 cells and viceversa. As shown in Figure 6B, MIA PaCa-2 supernatants containing all the secreted forms of ANXA1 protein $(37 \mathrm{kDa}, 33 \mathrm{kDa}$ and $3 \mathrm{kDa}$ ) significantly increased PANC-1 cell migration rate. Conversely, the administration of PANC-1 supernatants on MIA PaCa- 2 cells had no effects on migration speed of the latter ones. Moreover, the administration of MIA PaCa-2 conditioned supernatant containing ANXA1 blocking antibody on PANC-1 cells did not increase the migration rate of these cells.

\section{Discussion}

The role of ANXA1 in tumours is paradoxical since ANXA1 appears to behave either as a tumour suppressor or an oncogenic gene. As the mechanism of ANXA1 in cancer progression has not been still completely clarified, more studies are required to investigate the detailed action mechanisms of this protein in tumours. Accumulated evidences have indicated that ANXA1 deregulation and sub-cellular localization are involved in the development, invasion, metastasis and drug resistance of a variety of cancers suggesting a tissue type-specific role for ANXA1 in tumour advancing [9]. In particular, concerning cellular motility, ANXA1 actions are exerted extracellularly via FPRs in autocrine/paracrine manner, but also in the intracellular environment where it contributes to the dynamic reorganization of the actin cytoskeleton [11].

It has been shown that ANXA1 over-expression in the tissues from patients with PC is correlated with poor differentiation and prognosis and seems to be associated with malignant transformation and cancer progression [39-42].

In the present paper, we report that ANXA1 could have a role in PC cell migration and invasiveness and 


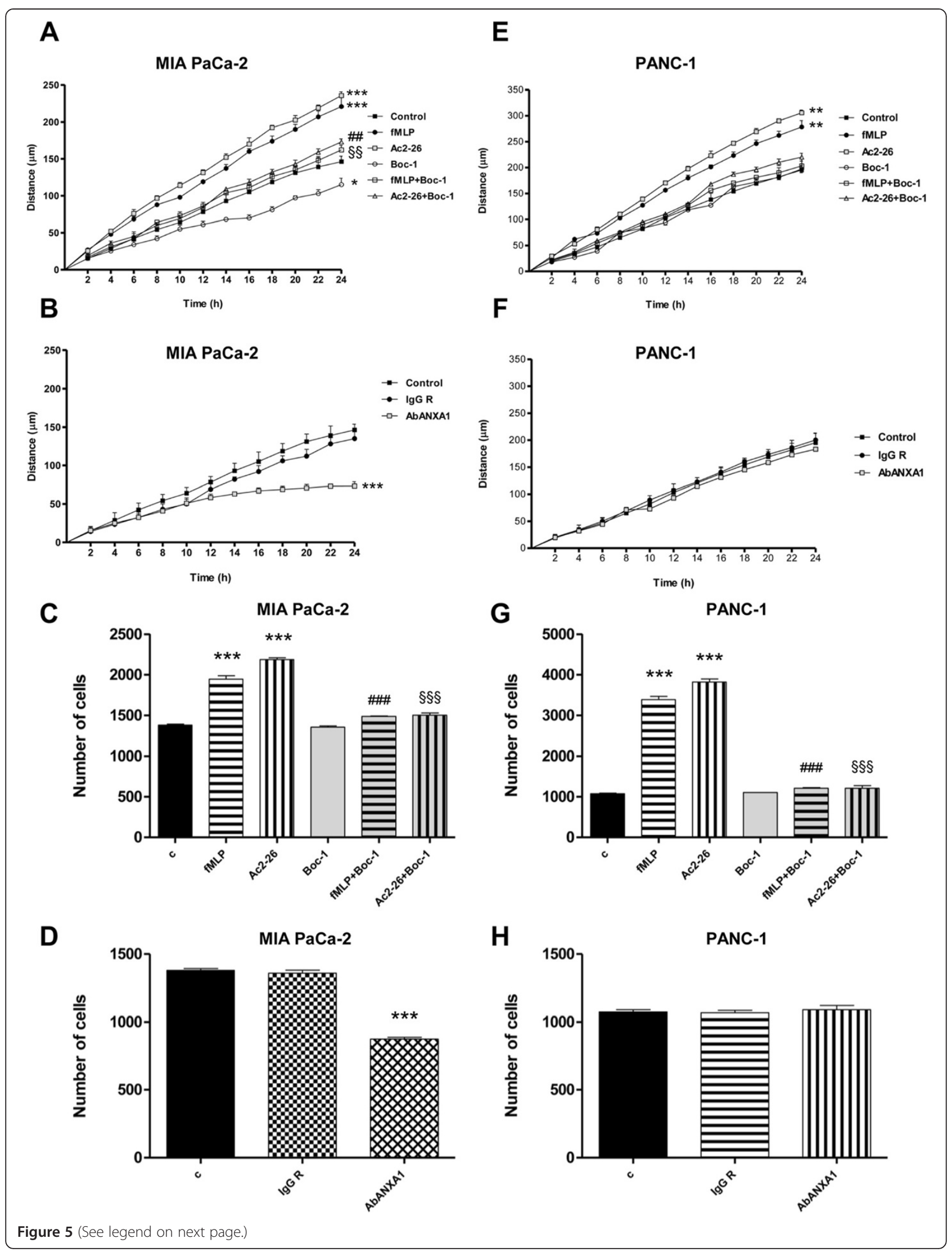


(See figure on previous page.)

Figure 5 Wound-healing and matrigel invasion assay on MIA PaCa-2 and PANC-1 cells. Wound-healing assay on MIA PaCa-2 (panel A) or PANC-1

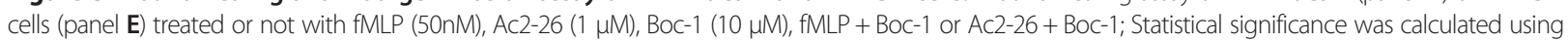
two way ANOVA, ${ }^{*} p<0.05,{ }^{* *} p<0.01,{ }^{* * *} p<0.001$ vs untreated control; ${ }^{\# \#} p<0.01$ and ${ }^{\S \S} p<0.01$ vs respective controls. Wound-healing assay on MIA PaCa-2 (panel B) or PANC-1 cells (panel F) treated or not with ANXA1 blocking antibody (AbANXA1) or scrambled rabbit lgG (lgG R); Statistical significance was calculated using unpaired $t$-test between control and treated cells, ${ }^{* * *} \mathrm{p}<0.001$ vs untreated control. All wound-healing data are representative of 5 experiments \pm SEM. Invasiveness rate of MIA PaCa-2 (panel C) or PANC-1 cells (panel G) treated or not with fMLP (50 nM), Ac2-26 (1 $\mu \mathrm{M})$, Boc-1 $(10 \mu \mathrm{M}), \mathrm{fMLP}+\mathrm{Boc}-1$ or Ac2-26+ Boc-1; Statistical significance was calculated using two way ANOVA, ${ }^{* * *} \mathrm{p}<0.001$ vs untreated control; \#\#\# $\mathrm{p}<0.001$ and ${ }^{\S \S \$} p<0.001$ vs respective controls. Invasiveness rate of MIA PaCa-2 (panel D) or PANC-1 cells (panel $\mathbf{H}$ ) treated or not with AbANXA1 or IgG R; Statistical significance was calculated using unpaired $t$-test between control and treated cells, ${ }^{* * *} p<0.001$ vs untreated control. Invasiveness rates were measured as described in Methods section. Data represent mean cell counts of 12 separate fields per well \pm SEM of 5 independent experiments.

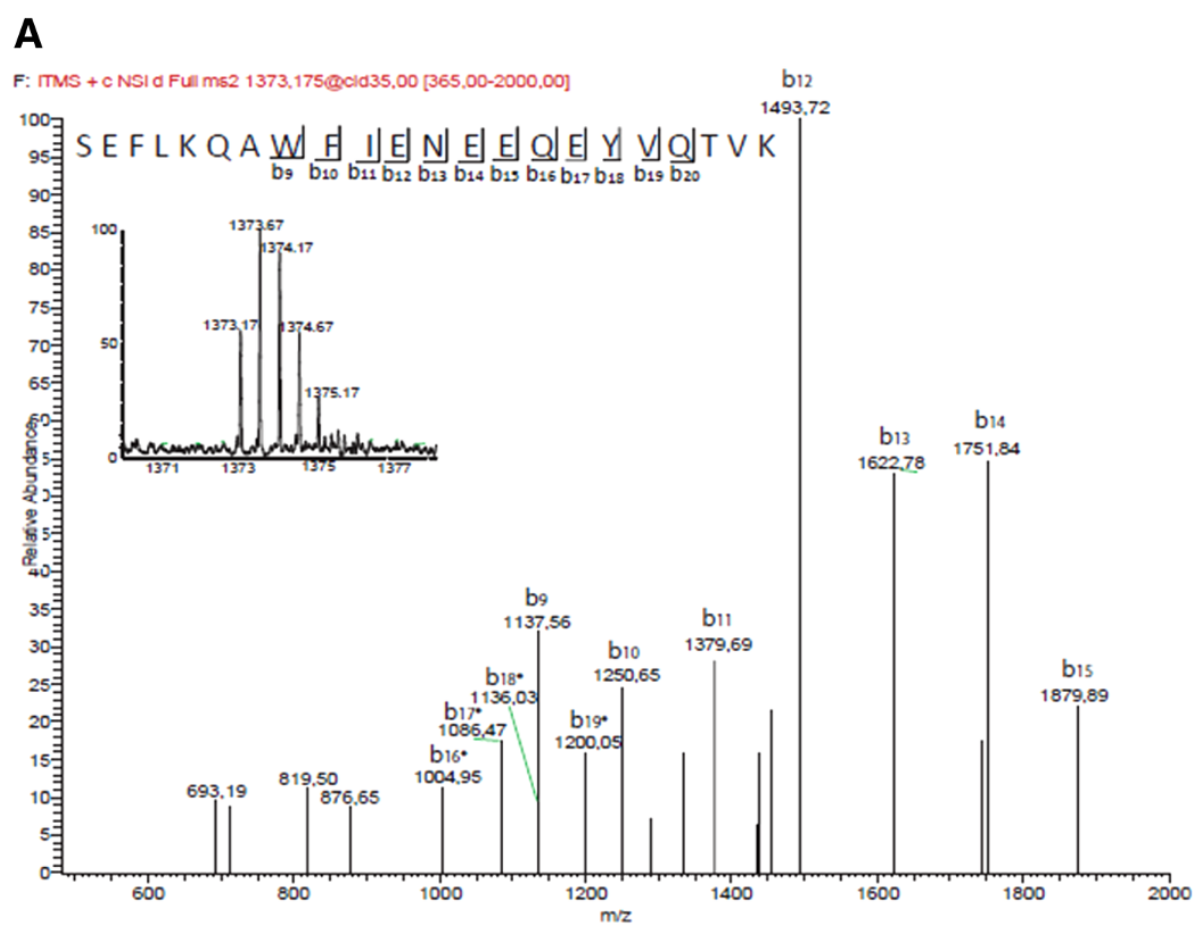

B

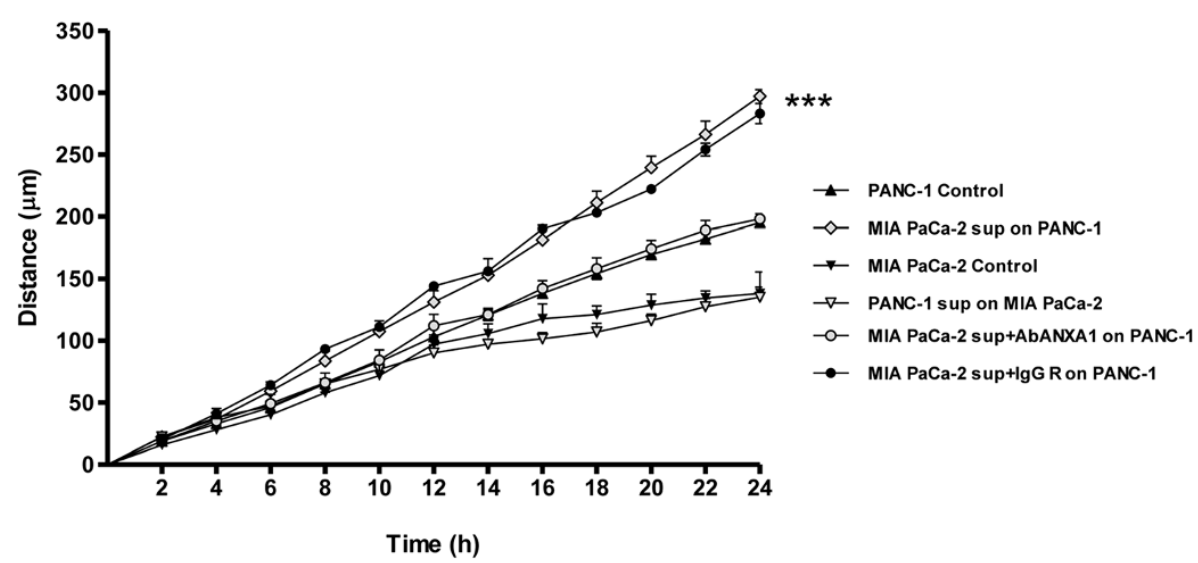

Figure 6 Analysis of the secreted forms of ANXA1 and of their effects on PC cell motility. A, LC-HRMS/MS spectrum, peaks refer to all the discovered peptide fragments. The data are representative of 5 experiments with similar results. B, Effects of MIA PaCa-2 supernatants on PANC-1 cells and viceversa in a wound-healing assay. Statistical significance was calculated using unpaired $t$-test between control and treated cells, ${ }^{* * *} p<0.001$. Data are means \pm SEM $(n=5)$. 
should be involved in the metastatic capability of these cells.

We first analyzed ANXA1 expression in MIA PaCa-2, PANC-1, BxPC-3 and CAPAN-2 PC cell lines and we found that all of them expressed high levels of ANXA1.

Moreover, all analyzed PC cell lines showed at least two different phenotypes: a less aggressive epithelial-like and a more aggressive mesenchymal-like. In the latter, ANXA1 was mainly localized in the regions involved in cellular motility, suggesting an intracellular role for the protein in the processes of cell migration/invasion.

Given the less aggressive phenotype of CAPAN-2 and BxPC-3 cells, we chose to use only MIA PaCa-2 and PANC-1 cells that present more marked mesenchymal features. In particular, among the other PC cell lines, MIA PaCa- 2 cells are commonly used to induce tumour xenografts in nude mice because of their strong capability to develop not only the largest tumoral mass but also metastasis [26].

Actually, the inhibition by siRNAs of ANXA1 expression in both MIA PaCa- 2 and PANC- 1 cells induced a significant decrease of the migration rate and markedly suppressed the invasiveness of these cells, confirming that intracellular ANXA1 is involved in PC cell migration/invasion.

ANXA1 has been shown to differently localize to the cellular compartments of various cell types including leukocytes, endothelial cells, lung epithelial cells and synoviocytes where it is thought to be important in biological functions [43-47]. Moreover, recent studies have shown that, in PC tissues, localization of ANXA1 was different in cytoplasm and membrane of tumour cells, indicating that the function of ANXA1 may vary among its differential localization.

We found that both MIA PaCa-2 and PANC-1 cells exhibit membrane and nuclear ANXA1 expression. ANXA1 membrane translocation has been reported to be strictly related to both membrane trafficking and secretion of the protein in extracellular environments and to be leaded by post-translational modifications [32]. Concerning the exact physiological functions of nucleartranslocated ANXA1 protein, accumulated evidence like in oral squamous cell carcinoma, gastric carcinoma and oesophageal squamous cell carcinoma, indicate that ANXA1 nuclear expression correlates with advanced disease and cancer dissemination. However, the mechanisms underlying ANXA1 nuclear translocation remain unknown [48-50].

We also found that MIA PaCa-2 cells exhibit increased extracellular ANXA1, so that we have hypothesized a role for the secreted protein in regulating PC cell migration/ invasion through the interaction with FPRs.

FPRs are expressed in several cellular populations and bind a variety of exogenous and endogenous ligands that elicit differential biological responses [16]. ANXA1 and its N-terminal mimetic peptide, Ac2-26, are endogenous FPR ligands. Flow cytometry and PCR analyses showed that MIA PaCa-2 and PANC-1 cells express FPR-1 and FPR-2. Moreover, experiments on the mobilization of intracellular calcium have confirmed the activity of the FPRs in these cell lines, following stimulation with the Ac2-26 peptide. We found no receptor activation in presence of Boc-1, a molecule that at a dose of $10 \mu \mathrm{M}$ can be considered as able to block all the three receptor isoforms [16].

Exogenous administration of Ac2-26 was also able to increase migration speed and invasiveness of cells through coating of matrigel, compared to relative controls. The specificity of Ac2-26-induced effects on wound closure and invasiveness through the FPRs was confirmed by administration of the FPR pan-antagonist Boc-1. The same results were obtained with ANXA1 blocking antibody, able to reduce PC cell motility in MIA PaCa-2 cells. Our results are consistent with the observed role of ANXA1 in head neck squamous cancers where the protein over-expression was associated with increased tumour invasiveness and metastasis and in SK-CO15 intestinal epithelial cells where ANXA1 regulated cellular invasive behaviour acting through FPRs [51,21].

Differently from MIA PaCa-2, no secreted forms of ANXA1 protein were observed in protein supernatant extracts from PANC-1 cells, consequently, we reasoned on the role of the extracellular protein in PC cell line migration and invasiveness. Results of a wound-healing migration assay on PANC-1 cells showed an increase in migration and invasiveness rate of cells treated with Ac2-26: these findings are consistent with the expression of FPR-1 and FPR-2 that we found in these cells. However, we showed that ANXA1 blocking antibody had no effects on PANC-1 cell motility.

We also report the presence of the full-length form $(37 \mathrm{kDa})$ accompanied by the appearance of the $33 \mathrm{kDa}$ cleavage product of ANXA1 in several cellular compartments of MIA PaCa-2 cells. Furthermore, these two forms are secreted outside the cells, since they appeared in cellular supernatants. LC-HRMS/MS, used to characterize secreted forms of ANXA1, showed a peptide with molecular weight of 2744.324 demonstrating, for the first time, the presence of the fragment 4-26 of ANXA1 in the extracellular environments.

In PC there is an abnormally high expression of a number of important tyrosine kinase growth factors and receptors, like the Epidermal Growth Factor (EGF) family, which may contribute to the neoplasia growth by autocrine and paracrine effects $[40,41]$. Immunohistochemistry studies showed that EGF Receptor (EGFR) over-expression positively correlates with advanced tumour staging and lymph node metastasis [42]. ANXA1 is a substrate protein of 
EGFR, so it can be postulated that constantly activated EGFR pathway could promote ANXA1 up-regulation and post-transductional modifications, which might be associated with its membrane translocation and secretion [52].

ANXA1 cleavage and secretion could be also mediated by several proteinases [53]: differential expression or activity of these enzymes could explain the lack of both ANXA1 cleavage and secretion in PANC-1 cells. However, further studies will be needed to address this point.

As previously reported, MIA $\mathrm{PaCa}-2$ have a more invasive behaviour than PANC-1 cells $[54,55]$ and we suppose that these differences could be due to the presence of secreted forms of ANXA1 protein. The addition of MIA PaCa-2 supernatant to PANC-1 cells significantly stimulated PANC-1 migration rate. Conversely, PANC-1 supernatant administration on MIA PaCa- 2 cells had no effects on cell motility, confirming that the secreted forms of ANXA1 protein may be able to induce PC cell migration and invasion.

The therapeutic properties of ANXA1 on wound closure are well known in other tissues and could be due to the autocrine and paracrine anti-inflammatory effects of its $\mathrm{N}$-terminus peptide, Ac2-26, that is released from the full length protein through regulated proteolysis [56]. It has recently shown that both the full length protein and the Ac2-26 peptide promote cell motility in intestinal epithelial cells through FPRs [57]. Our studies are consistent with these findings and could explain the biological effects of ANXA1 and its cleavage products on the ability of MIA PaCa-2 cells to have a more invasive behaviour.

\section{Conclusions}

In summary, our data suggest a role for intracellular and extracellular ANXA1 in stimulating PC cell migration and invasion. However, future studies on $\mathrm{PC}$ patients will be needed to determine whether ANXA1 could represent a potential diagnostic, prognostic or predictive biomarker by correlating the progression and/or metastatic rate of the tumour to the protein expression.

\section{Competing interests}

The authors declare that they have no competing interests.

\section{Authors' contributions}

Study conception and design: RB, VB, LP, AP. Acquisition of data: RB and VB (cell culture and gene silencing, protein extracts, western blot, wound-healing assay, PCR, flow cytometry, immunofluorescences, matrigel invasion assay), AP (Popolo) (FURA assay), FDP (LC/MS/MS), MV (LC/MS/MS), PP (matrigel invasion assay) Analysis and interpretation of data: RB, VB, AP. Drafting of manuscript: $R B, V B, L P, A P$. Critical revision: LP, AP. The work presented here was carried out in collaboration between all authors. All authors have read and approved the final manuscript.

\section{Acknowledgements}

The work conducted in our laboratory and referred to in this paper was funded by University of Salerno (FARB 2012, 2013).

Received: 17 July 2014 Accepted: 11 December 2014

Published: 16 December 2014

\section{References}

1. Jemal A, Siegel R, Xu J, Ward E: Cancer statistics. CA Cancer J Clin 2010, 60:277-300.

2. Bardeesy N, DePinho RA: Pancreatic cancer biology and genetics. Nat Rev Cancer 2002, 2:897-909.

3. Komoto M, Nakata B, Nishii T, Kawajiri H, Shinto O, Amano R, Yamada N, Yashiro $M$, Hirakawa $K$ : In vitro and in vivo evidence that a combination of lapatinib plus S-1 is a promising treatment for pancreatic cancer. Cancer Sci 2010, 101:468-473.

4. Winter JM, Yeo CJ, Brody JR: Diagnostic, prognostic, and predictive biomarkers in pancreatic cancer. J Surg Oncol 2013, 107:15-22.

5. Ferrone CR, Pieretti-Vanmarcke R, Bloom JP, Zheng H, Szymonifka J, Wargo JA, Thayer SP, Lauwers GY, Deshpande V, Mino-Kenudson M, Fernàndez-del Castillo C, Lillemoe KD, Warshaw AL: Pancreatic ductal adenocarcinoma: long-term survival does not equal cure. Surgery 2012, 152:S43-S49.

6. Keleg S, Büchler P, Ludwig R, Büchler MW, Friess H: Invasion and metastasis in pancreatic cancer. Mol Cancer 2003, 2:14.

7. Lim LHK, Pervaiz S: Annexin 1: the new face of an old molecule. FASEB J 2007, 21:968-975.

8. Fatimathas L, Moss SE: Annexins as disease modifiers. Histol Histopathol 2010, 25:527-532.

9. Guo C, Liu S, Sun MZ: Potential role of Anxa1 in cancer. Future Oncol 2013, 9:1773-1793.

10. Boudhraa Z, Rondepierre F, Ouchchane L, Kintossou R, Trzeciakiewicz A, Franck F, Kanitakis J, Labeille B, Joubert-Zakeyh J, Bouchon B, Perrot JL, Mansard S, Papon J, Dechelotte P, Chezal JM, Miot-Noirault E, Bonnet M, D'Incan M, Degoul F: Annexin A1 in primary tumors promotes melanoma dissemination. Clin Exp Metastasis 2014, [Epub ahead of print] doi:10.1007/ s10585-014-9665-2.

11. Bizzarro V, Fontanella B, Franceschelli S, Pirozzi M, Christian H, Parente L, Petrella A: Role of Annexin A1 in mouse myoblast cell differentiation. J Cell Physiol 2010, 224:757-765.

12. Bizzarro V, Belvedere R, Dal Piaz F, Parente L, Petrella A: Annexin A1 induces skeletal muscle cell migration acting through formyl peptide receptors. PLoS One 2012, 7:e48246.

13. Bizzarro V, Fontanella B, Carratù A, Belvedere R, Marfella R, Parente L, Petrella A: Annexin A1 N-terminal derived peptide Ac2-26 stimulates fibroblast migration in high glucose conditions. PLoS One 2012, 7:e45639.

14. de Graauw M, van Miltenburg MH, Schmidt MK, Pont C, Lalai R, Kartopawiro J, Pardali E, Le Dévédec SE, Smit VT, van der Wal A, Van't Veer LJ, Cleton-Jansen AM, ten Dijke $P$, van de Water B: Annexin A1 regulates TGF-beta signaling and promotes metastasis formation of basal-like breast cancer cells. Proc Natl Acad Sci U S A 2011, 107:6340-6345.

15. Cheng TY, Wu MS, Lin JT, Lin MT, Shun CT, Huang HY, Hua KT, Kuo ML: Annexin A1 is associated with gastric cancer survival and promotes gastric cancer cell invasiveness through the formyl peptide receptor/ extracellular signal-regulated kinase/integrin beta-1-binding protein 1 pathway. Cancer 2012, 118:5757-5767.

16. Ye RD, Boulay F, Wang JM, Dahlgren C, Gerard C, Parmentier M, Serhan CN, Murphy PM: International Union of Basic and Clinical Pharmacology. LXXIII. Nomenclature for the formyl peptide receptor (FPR) family. Pharmacol Rev 2009, 61:119-161.

17. Huang J, Chen K, Chen J, Gong W, Dunlop NM, Howard OM, Gao Y, Bian XW, Wang JM: The G-protein coupled formylpeptide receptor FPR confers a more invasive phenotype on human glioblastoma cells. Br J Cancer 2010, 102:1052-1060.

18. Huang J, Chen K, Gong W, Dunlop NM, Wang JM: G-protein coupled chemoattractant receptors and cancer. Front Biosci 2008, 13:3352-3363.

19. Zhou Y, Bian X, Le Y, Gong W, Hu J, Zhang X, Wang L, Iribarren P, Salcedo R, Howard OM, Farrar W, Wuang JM: Formylpeptide receptor FPR and the rapid growth of malignant human gliomas. J Natl Cancer Inst 2005, 97:823-835.

20. Yang Y, Liu Y, Yao X, Ping Y, Jiang T, Liu Q, Xu S, Huang J, Mou H, Gong W, Chen $K$, Bian $X$, Wang JM: Annexin 1 released by necrotic human glioblastoma cells stimulates tumor cell growth through the formyl peptide receptor 1. Am J Pathol 2011, 179:1504-1512.

21. Babbin BA, Lee WY, Parkos CA, Winfree LM, Akyildiz A, Perretti M, Nusrat A: Annexin I regulates SKCO-15 cell invasion by signaling through Formyl Peptide Receptors. J Biol Chem 2006, 28:19588-19599.

22. de Coupade C, Solito E, Levine JD: Dexamethasone enhances interaction of endogenous annexin 1 with L-selectin and triggers shedding of L-selectin in the monocytic cell line U-937. Br J Pharmacol 2003, 140:133-145. 
23. Dal Piaz F, Cotugno R, Lepore L, Vassallo A, Malafronte N, Lauro G, Bifulco G, Belisario MA, De Tommasi N: Chemical proteomics reveals HSP70 1A as a target for the anticancer diterpene oridonin in Jurkat cells. J Proteomics 2013, 82:14-26.

24. Montinaro A, Forte G, Sorrentino R, Luciano A, Palma G, Arra C, Adcock IM, Pinto A, Morello S: Adoptive immunotherapy with Cl-IB-MECA-treated $\mathrm{CD}^{+}$T cells reduces melanoma growth in mice. PLoS One 2012, 7:e45401.

25. Adesso S, Popolo A, Bianco G, Sorrentino R, Pinto A, Autore G, Marzocco S: The uremic toxin indoxyl sulphate enhances macrophage response to LPS. PLoS One 2013, 8:e76778.

26. Deer EL, González-Hernández J, Coursen JD, Shea JE, Ngatia J, Scaife CL, Firpo MA, Mulvihill SJ: Phenotype and genotype of pancreatic cancer cell lines. Pancreas 2010, 39:425-435.

27. Thiery JP: Epithelial-mesenchymal transitions in development and pathologies. Curr Opin Cell Biol 2003, 15:740-746.

28. Huber MA, Kraut N, Beug H: Molecular requirements for epithelial mesenchymal transition during tumor progression. Curr Opin Cell Biol 2005, 17:548-558.

29. Salnikov AV, Liu L, Platen M, Gladkich J, Salnikova O, Ryschich E, Mattern J, Moldenhauer G, Werner J, Schemmer P, Büchler MW, Herr I: Hypoxia induces EMT in low and highly aggressive pancreatic tumor cells but only cells with cancer stem cell characteristics acquire pronounced migratory potential. PLoS One 2012, 7:e46391

30. Bergman A, Condeelis JS, Gligorijevic B: Invadopodia in context. Cell Adh Migr 2014, 8. [Epub ahead of print] doi:10.4161/cam.28349.

31. Li S, Guan JL, Chien S: Biochemistry and biomechanics of cell motility. Annu Rev Plant Physiol Plant Mol Biol 2005, 7:105-150.

32. Solito E, Christian HC, Festa M, Mulla A, Tierney T, Flower RJ, Buckingham JC: Post-translational modification plays an essential role in the translocation of annexin A1 from the cytoplasm to the cell surface. FASEB J 2006, 20:1498-1500.

33. Hullin F, Raynal P, Ragab-Thomas JM, Fauvel J, Chap H: Effect of dexamethasone on prostaglandin synthesis and on lipocortin status in human endothelial cells. Inhibition of prostaglandin 12 synthesis occurring without alteration of arachidonic acid liberation and of lipocortin synthesis. J Biol Chem 1989, 264:3506-3513.

34. Ambrose MP, Hunninghake GW: Corticosteroids increase lipocortin I in alveolar epithelial cells. Am J Respir Cell Mol Biol 1990, 3:349-353.

35. Croxtall JD, Choudhury Q, Newman S, Flower RJ: Lipocortin 1 and the control of CPLA2 activity in A549 cells. Glucocorticoids block EGF stimulation of cPLA2 phosphorylation. Biochem Pharmacol 1996, 52:351-356.

36. Perretti M, Croxtall JD, Wheller SK, Goulding NJ, Hannon R, et al: Mobilizing lipocortin 1 in adherent human leukocytes downregulates their transmigration. Nat Med 1996, 2:1259-1262.

37. Rhee HJ, Kim GY, Huh JW, Kim SW, Na DS: Annexin I is a stress protein induced by heat, oxidative stress and a sulfhydryl-reactive agent. Eur J Biochem 2000, 267:3220-3225.

38. Sampey AV, Hutchinson P, Morand EF: Annexin I surface binding sites and their regulation on human fibroblast-like synoviocytes. Arthritis Rheum 2000, 43:2537-2542.

39. Bai XF, Ni XG, Zhao P, Liu SM, Wang HX, Guo B, Zhou LP, Liu F, Zhang JS, Wang K, Xie YQ, Shao YF, Zhao XH: Overexpression of annexin 1 in pancreatic cancer and its clinical significance. World J Gastroenterol 2004, 10:1466-1470

40. Chen CY, Shen JQ, Wang F, Wan R, Wang XP: Prognostic significance of annexin A1 expression in pancreatic ductal adenocarcinoma. Asian Pac $J$ Cancer Prev 2012, 13:4707-4712

41. Coppola D: Molecular prognostic markers in pancreatic cancer. Cancer Control 2000, 7:421-427.

42. Liu K, Qin CK, Wang ZY, Liu SX, Cui XP, Zhang DY: Expression of tumour necrosis factor-alpha-induced protein 8 in pancreas tissues and its correlation with epithelial growth factor receptor levels. Asian Pac $J$ Cancer Prev 2012, 13:847-850

43. Haigler HT, Schlaepfer DD: Annexin I phosphorylation and secretion In The Annexins. Edited by Moss SE. London; Portland Press; 1992:11-34.

44. Rescher U, Danielczyk A, Markoff A, Gerke V: Functional activation of the formyl peptide receptor by a new endogenous ligand in human lung A549 cells. J Immunol 2002, 169:1500-1504.

45. Gavins FN, Yona S, Kamal AM, Flower RJ, Perretti M: Leukocyte antiadhesive actions of annexin 1: ALXR- and FPR-related anti-inflammatory mechanisms. Blood 2003, 101:4140-4147.
46. Solito E, Raugei G, Melli M, Parente L: Dexamethasone induces the expression of the mRNA of lipocortin 1 and 2 and the release of lipocortin 1 and 5 in differentiated, but not undifferentiated U-937 cells. FEBS Lett 1991, 291:238-244.

47. Côtè MC, Lavoie JR, Houle F, Poirier A, Rousseau S, Huot J: Regulation of vascular endothelial growth factor-induced endothelial cell migration by LIM Kinase 1-mediated phosphorylation of Annexin 1. J Biol Chem 2010, 285:8013-8021.

48. Lin CY, Jeng YM, Chou HY, Hsu HC, Yuan RH, Chiang CP, Kuo MY: Nuclear localization of annexin $\mathrm{A} 1$ is a prognostic factor in oral squamous cell carcinoma. J Surg Oncol 2008, 97:544-550.

49. Zhu F, Xu C, Jiang Z, Jin M, Wang L, Zeng S, Teng L, Cao J: Nuclear localization of annexin A1 correlates with advanced disease and peritoneal dissemination in patients with gastric carcinoma. Anat Rec (Hoboken) 2010, 293:1310-1314.

50. Han G, Tian Y, Duan B, Sheng H, Gao H, Huang J: Association of nuclear annexin $\mathrm{A} 1$ with prognosis of patients with esophageal squamous cell carcinoma. Int J Clin Exp Pathol 2014, 7:751-759.

51. Wu W, Tang X, Hu W, Lotan R, Hong WK, Mao L: Identification and validation of metastasis-associated proteins in head and neck cancer cell lines by two-dimensional electrophoresis and mass spectrometry. Clin Exp Metastasis 2002, 19:319-326.

52. Pepinsky RB, Sinclair LK: Epidermal growth factor-dependent phosphorylation of lipocortin. Nature 1986, 321:81-84.

53. Kwon JH, Lee JH, Kim KS, Chung YW, Kim IY: Regulation of cytosolic phospholipase A2 phosphorylation by proteolytic cleavage of annexin A1 in activated mast cells. J Immunol 2012, 188:5665-5673.

54. Takada M, Nakamura Y, Koizumi T, Toyama H, Kamigaki T, Suzuki Y, Takeyama Y, Kuroda Y: Suppression of human pancreatic carcinoma cell growth and invasion by epigallocatechin-3-gallate. Pancreas 2002, 25:45-48.

55. Ellenrieder V, Hendler SF, Ruhland C, Boeck W, Adler G, Gress TM: TGF-beta-induced invasiveness of pancreatic cancer cells is mediated by matrix metalloproteinase-2 and the urokinase plasminogen activator system. Int J Cancer 2001, 93:204-211.

56. Perretti M, D'Acquisto F: Annexin A1 and glucocorticoids as effectors of the resolution of inflammation. Nat Rev Immunol 2009, 9:62-70.

57. Leoni G, Alam A, Neumann PA, Lambeth JD, Cheng G, McCoy J, Hilgarth RS, Kundu K, Murthy N, Kusters D, Reutelingsperger C, Perretti M, Parkos CA, Neish AS, Nusrat A: Annexin A1, formyl peptide receptor, and NOX1 orchestrate epithelial repair. J Clin Invest 2013, 123:443-454.

doi:10.1186/1471-2407-14-961

Cite this article as: Belvedere et al:: Role of intracellular and extracellular annexin $\mathrm{A} 1$ in migration and invasion of human pancreatic carcinoma cells. BMC Cancer 2014 14:961.

\section{Submit your next manuscript to BioMed Central and take full advantage of:}

- Convenient online submission

- Thorough peer review

- No space constraints or color figure charges

- Immediate publication on acceptance

- Inclusion in PubMed, CAS, Scopus and Google Scholar

- Research which is freely available for redistribution 